\title{
A SURVEY ON TOPICS, RESEARCHERS AND CULTURES IN THE FIELD OF DIGITAL HERITAGE
}

\author{
S. Münster ${ }^{\mathrm{a}}$ \\ ${ }^{a}$ Media Center, Technische Universität Dresden, D-01062 Dresden, Germany - sander.muenster@tu-dresden.de
}

Commission II, WG VI/4

KEY WORDS: Digital heritage, Survey, Topics, Scholarly Area

\begin{abstract}
:
Digital heritage comprises a broad variety of approaches and topics and involves researchers from multiple disciplines. While the use of digital methods in the text-oriented disciplines dealing with cultural heritage is widely discussed and canonized, an up-to-date investigation on cultural heritage as a scholarly field is currently missing. The extended abstract is about a three-stage investigation on standards, publications, disciplinary cultures as well as scholars in the field of digital heritage, carried out in 2016 and 2017. It includes results of a workshop-based survey involving 44 researchers, 15 qualitative interviews as well as an online survey with nearly 1000 participants. As an overall finding, a community is driven by researchers from European countries and especially Italy with a background in humanities, dealing with topics of data acquisition, data management and visualization. Moreover, conference series are most relevant for a scientific discourse, and especially EU projects set pace as most important research endeavours.
\end{abstract}

\section{INTRODUCTION}

Digital heritage comprises a broad variety of approaches and topics and involves researchers from multiple disciplines. While the use of digital methods in the text-oriented disciplines dealing with cultural heritage is widely discussed and canonized (eg. Svensson, 2010; Terras et al., 2013), an up-to-date investigation on cultural heritage as a scholarly field is currently missing. Possible reasons may be seen in the "diverse nature of the methods used in art history" and adjacent disciplines (Long and Schonfeld, 2014, p. 48), but also in the heterogeneous level of establishment of digital research methods in disciplines related to cultural heritage (Hicks, 2006). But what are characteristics of an academic area? A therefore prominent approach characterizes fields of research by specific epistemic cultures in terms of different "architectures of empirical approaches, specific constructions of the referent, particular ontologies of instruments, and different social machines" (Knorr-Cetina, 1999, p. 3), different approaches to gain insights, different vocabularies, different publication bodies and habits (Cetina and Reichmann, 2015). On a more operational level, disciplines are characterised to „(a) have a particular object of research [...], (b) have a body of accumulated specialist knowledge [...], (c) have theories and concepts [...], (d) use specific terminologies [...], (d) have developed specific research methods [...], and (e) must have some institutional manifestation in the form of subjects taught at universities or colleges [...]” (Krishnan, 2009).

Against this background, my research is intended to investigate a range of digital heritage studies with regards to the following questions:

- What are research areas and topics in the field of digital heritage?

- What are leading publications and projects?

\section{RELATED WORK}

\section{Digital heritage as scholarly area}

With regards to a scholarly area of digital heritage and its adjacent field of digital humanities, Hicks et al. (Hicks, 2006) stated that publication habits as well as research habits widely differ between single disciplines in the (digital) humanities. With regards to a scholarly community in digital humanities, Terras (Terras, 2006) examined that especially US, Canadian and UK-based researchers contributed to an academic discourse until 2006. Scott et al. performed a similar analysis for the Digital Humanities 2017 conference submissions (Weingart, 2016). While a community in Terras' analysis exclusively dealt with textual and - few - image sources, digital heritage related aspects such as visualization, geospatial analysis or VR/AR got into the top 50 keyword list. With regards to digital heritage, Scollar (Scollar, 1997) investigated the Conference on Computer Application in Archaeologies (CAA) from 1971 to 1996, and Münster and Ioannides (Münster and Ioannides, 2015) investigated the Proceedings of CAA, DH, CIPA, VAST, 3DArch and EUROMED between 1990 and 2015. As a finding of both studies, researchers in the fields of digital heritage are primarily located in Mediterranean countries and have backgrounds in various disciplines - including computing, humanities, architecture and geo- and natural sciences. An academic discourse takes mainly place on technology-related topics as well as dealing especially with architectural heritage.

\section{Topics and methods in digital heritage}

What are research topics and methods? A general overview on cultural heritage as a research area in the first years of the millennium was described by the EPOCH project (Arnold and Geser, 2008). Particularly with regards to the use of digital methods in cultural heritage and digital humanities, Drucker (Drucker, 2013) sketches a historical evolution as well as a current state of application of digital methods in humanities. Additionally, both Heusinger (Heusinger, 1989) and Kohle (Kohle, 2013) define fields of supplement by digital tools and practices in research processes related to cultural heritage. Similarly, many texts describe a comprehensive state of the art and methodologies for digital archaeology (e.g. Evans and Daly, 2006; Frischer and Dakouri-Hild, 2008; Kansa et al., 2011). Furthermore, there are many standards and guidelines as well as rules defined and discussed for dealing with historical content (Beacham et al., 2006; Bendicho, 2011; Kiouss et al., 2011; 
Pfarr, 2009; Sürül et al., 2003). In contrast, there is little empirical research on practices and users of digital heritage (c.f. Huvila, 2014).

\section{RESEARCH}

\subsection{Research Design}

In-conference survey

From a theoretical point of view, the communities of practice approach originally introduced by Lave \& Wenger (Lave and Wenger, 1991) defines that these communities are marked by mutual engagement, a joint enterprise as well as a shared repertoire of knowledge and culture (Wenger, 1998). A resultant assumption is that publications such as conference papers and journals are main podia for knowledge sharing in academia. Consequently, the investigation of conferences dealing with that topic is my primary approach to discover a research community on digital cultural heritage. My research started with a series of questionnaire-based surveys on research topics, podia and standards which took place during a track on Visual Knowledge management at the International Forum for Knowledge Asset Management (IFKAD) and the ARKDIS conference on information in archaeology, both held in June 2016 (Münster and Niebling, 2016) as well as during a lecture held at City University in London in the department of human computer interaction in October 2016. In total, 44 researchers participated. Since these investigations represented very specific facets of digital cultural heritage, these were done to gain a general overview on topics and standards of relevance.

\section{Qualitative interviews}

An adjacent interest was to investigate research topics and methods and scholarly culture more in detail. I interviewed 15 researchers at several universities in London between September and November 2016, via guideline-based expert interviews (Gläser and Laudel, 2009; Mieg and Näf, 2005). An analysis of data is proposed to take place using approaches of qualitative content analysis (Mayring, 2008) to (1) inductively gain an initial category scheme and (2) deduce it to further materials. An expected outcome of that step comprises both an inductively generated categorization scheme as well as a set of related variables and occurrences.

\section{Online Survey}

Since various phenomena have been identified via these investigations, a follow-up interest was to investigate these issues for a larger number of researchers. For thus, another survey included all authors from CAA, CIPA, VAST, Digital Heritage, 3DArch and EUROMED conference series proceedings dating between 1990 and 2015 (Münster, 2017). I extracted all provided email addresses published under the author information section - in total 4211 addresses out of 3996 publications. Against this background, several factors were limiting

1. Only recent publications contain email addresses of authors.

2. Often only the email address of the first author is included.

3. Nearly $1 / 4$ of the email addresses (1063 of 4211) do not exist anymore.

The survey took place over two weeks in March 2017 and included 3148 valid email addresses. 988 people participated and 602 completed the survey. Since the questions were not depending on each other, responses from non-finishers were included in evaluation, too. Evaluation took place based on the category scheme developed during the qualitative interviews as well as by employing inductive and deductive content analysis.

\section{Findings}

The research stages delivered various insights in careers, topics, publication and research habits as well as organizational habits in digital heritage and the adjacent area of visual-oriented digital humanities research. Following, some aspects will be exemplified.

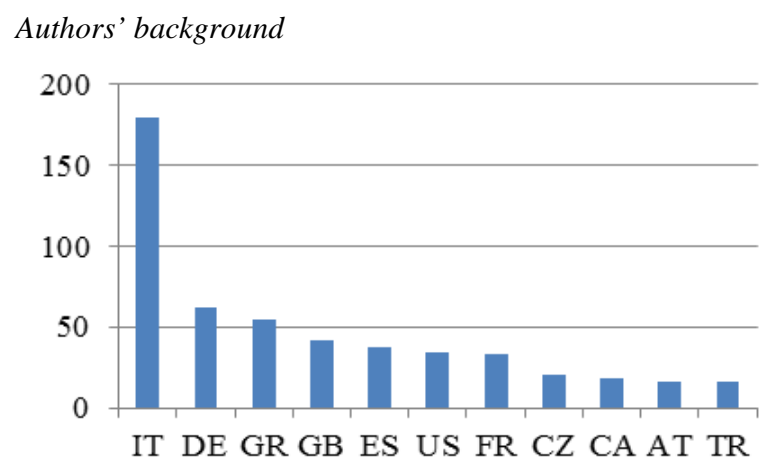

Figure 1 . Nationality (Online Survey, top 10 out of $n=693$ )

What is the background of people who are active in the field of cultural heritage? Despite various attempts to attract researchers from other parts of the world, e.g. at conference locations in non-European countries, a community is primarily European. As stated in former studies (European Commission, 2011; Münster and Ioannides, 2015), a majority of researchers in the field of digital cultural heritage is Italian, followed by Germans and Greek. What are disciplinary backgrounds of authors? To classify research areas we followed the Frascati manual offered by OECD (Organisation for Economic Co-operation and Development, 2002). Other schemes are rather outdated, such as CERIF (n.n., 1991), with resultant weaknesses esp. with regards to the distinction of computing areas or the limited compatibility to a European situation - as the American NCES scheme (NCES IPEDS, 2010). To make our research comparable to former investigations, we grouped (1) all georelated disciplines, i.e. cartography, surveying and geodesy, and (2) all architectural disciplines.

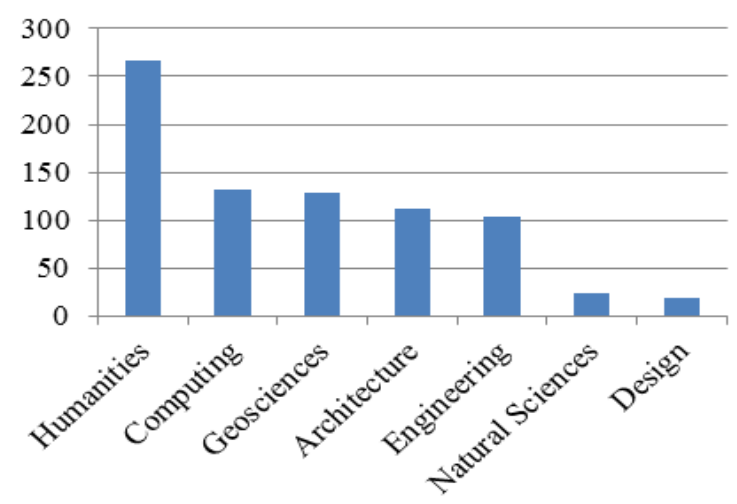

Figure 2. Disciplinary background (Online Survey, n=782)

A majority of participants assorted themselves to humanities, most frequently named within was archaeology. The high rate of researchers in that field stood in contrast to our former 
investigations, where especially the rate of computing was much higher (c.f. Fig. 3). It may be assumed that especially engineers and architects - whose rate is significant higher in the survey (1) work in departments dedicated to computing or (2) - since each authorship was counted in the literature-based assignment - are having a lower publication output than researchers in computing.

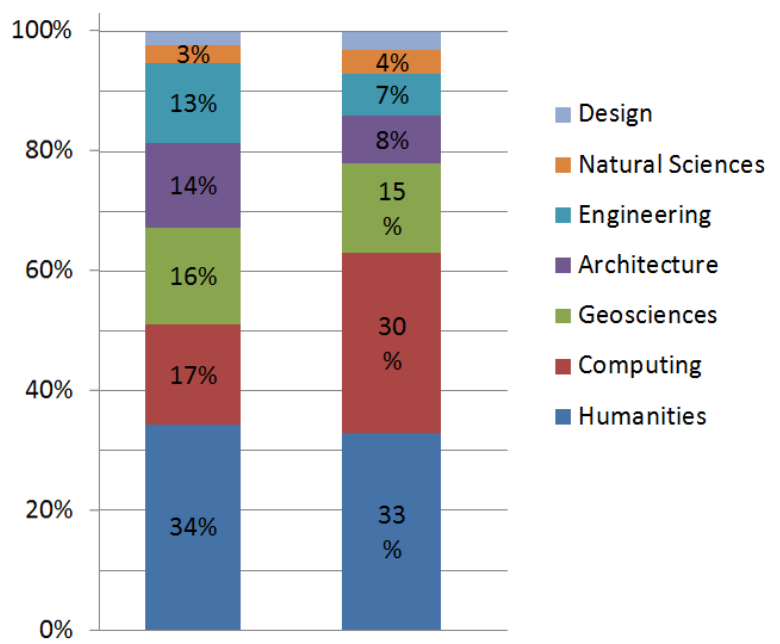

Figure 3. Disciplinary background (left column: online survey, $\mathrm{n}=782$, right column: manual tagging of authors by institution, $\mathrm{n}=1232$. This was originally published in (Münster and Ioannides, 2015)

What are research areas and topics?

As derived from former research (Münster, 2017), an academic discourse in the field of digital heritage is widely driven by technological topics - especially aspects of data acquisition and management (cf. Table 1). In contrast, specific humanitiesrelated approaches on "methods" or "analysis" are only occasionally named. A third group of research topics deals with social issues of digital heritage like aspects of communication such as crowdsourcing and virtual exhibitions or user practices.

\begin{tabular}{|c|c|c|}
\hline Category & Count & Examples \\
\hline $\begin{array}{l}\text { Data } \\
\text { management }\end{array}$ & 11 & $\begin{array}{l}\text { e.g. GIS, BIM, databases, } \\
\text { metadata }\end{array}$ \\
\hline Data acquisition & 6 & Photogrammetry, laser scan \\
\hline Communication & 6 & $\begin{array}{l}\text { e.g. museum exhibition, } \\
\text { crowdsourcing }\end{array}$ \\
\hline Analysis & 6 & $\begin{array}{l}\text { e.g. visual or spatial } \\
\text { analysis, computer vision }\end{array}$ \\
\hline Visualisation & 5 & e.g. virtual reality, drawing \\
\hline Methods & 4 & \\
\hline Modelling & 2 & $\begin{array}{l}\text { e.g. } \quad 3 \mathrm{D} \quad \text { modelling, } \\
\text { reconstruction }\end{array}$ \\
\hline User Practices & 2 & \\
\hline Documentation & 1 & \\
\hline Education & 1 & \\
\hline Others & 9 & \\
\hline
\end{tabular}

Table 1. "What are your fields of research related to archaeological information/visual humanities?” (carried out on ARKDIS conference, 23 contributors, 76 answers)

With regards to the relevance of individual topics (c.f. Fig. 4), especially data management was most frequently named, ranging from GIS and BIM to metadata schemes and data architecture, followed by data acquisition, analysis and visualisation.

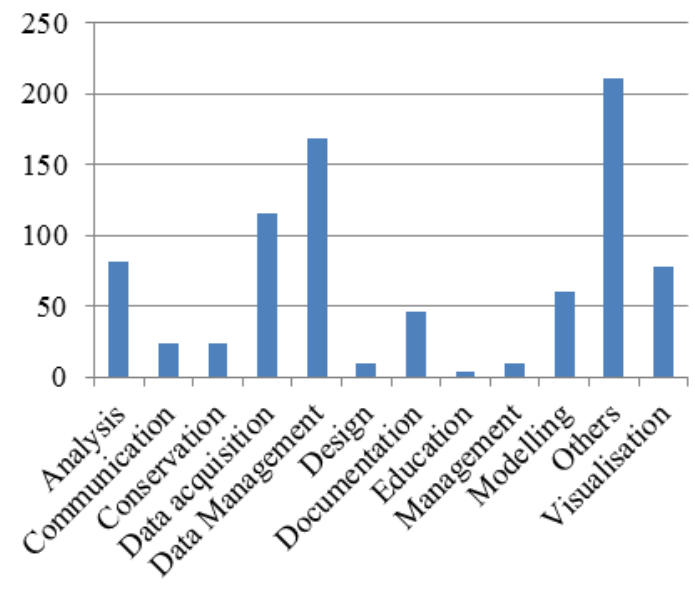

Figure 4. Topics (online survey, n=825)

As an additional note on the survey carried out at ARKDIS, numerous researchers work on topics of conservation or on the non-digital management of heritage objects. A large number of answers did not fit into the predefined categories and were subsumed in "Others" - in most cases disciplinary approaches, epochs or objects were named. Similarly, a majority of interviewees in the qualitative interview series estimated the access to data as "biggest challenge" of digital humanities, as mentioned by a $\mathrm{PhD}$ student in geosciences. That includes for instance aspects of data availability which is limited by legal barriers or company ownership. Since "much data is being shared [via] services like Facebook", it is - as mentioned by a research coordinator - "[potentially] going to be locked away and inaccessible” for researchers. Moreover, with regards to aspects of long term preservation and availability "we can't rely on commercial companies to pay [attention] for this". Furthermore, and beside the vast amount of data which is not available online for various reasons, much data is currently not accessible due to insufficient tagging, indexing or linking. As a consequence, "we don't really know what's in there, if [...] a web page [links to] [...] broken images". Finally, this relates to the question how to archive and preserve digital data like “digital art”.

What are standards in digital heritage?

\begin{tabular}{|l|r|}
\hline Item & Count \\
\hline Publications & 20 \\
Repositories & 12 \\
Projects & 8 \\
Institutions & 5 \\
Standards & 4 \\
not recognizeable & 4 \\
Methods & 2 \\
Others & 1 \\
\hline
\end{tabular}

Table 2. "What are 'gold standards' in your field of research?" (21 contributors, 56 answers)

While both publications and projects were named as anchor examples in the questionnaire manual, it was remarkable that various data repositories and services were named as "standards" (cf. Table 2), which underlines the high relevance 


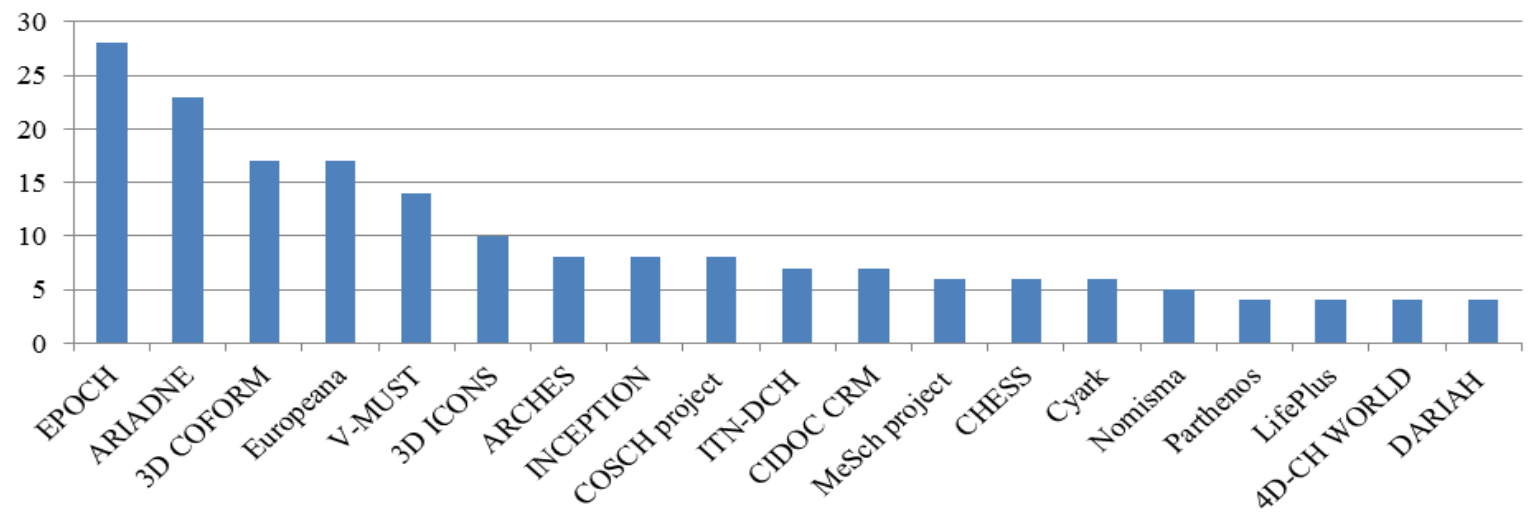

Figure 5. Projects named as "most relevant” (online survey, N>3, n=186 out of 1024 named projects)

of data as well as the availability of high-quality infrastructure suppliers.

With regards to publications, both conference series and journals were named nearly equally often, but no books or book series were mentioned. Moreover, "methods" - even if named as anchor example - were named only occasional. An explanation may be that digital heritage is - as mentioned by a head of digital museum technologies - "around the subject", incorporating a wide plurality of contributing institutions as well as methods and approaches.

\section{What are most relevant publication bodies?}

Against that background we queried within the online survey which podia were estimated as most relevant. Since we selected the sample on the base of specific conference series, we assumed that results will be biased esp. with regards to named conferences. Nevertheless we expected (1) to query further podia and especially journals of relevance as well as (2) to derive a ranking of publications.

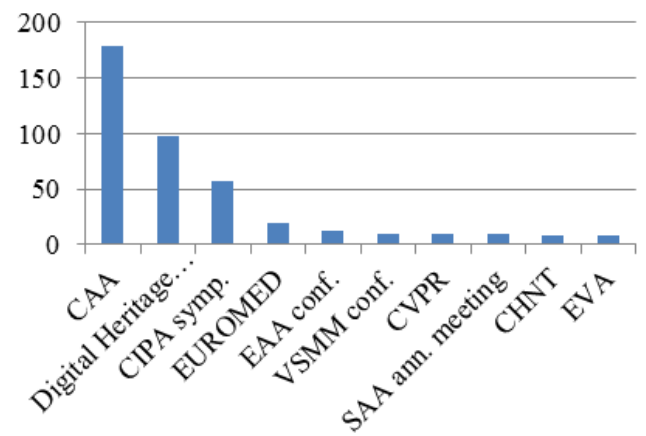

Figure 6. Conference series named as "most relevant” (online survey, top $10, n=411$ out of 1382 named publications)

With regards to conference series named, especially the CAA series was mentioned as most relevant (Fig. 6), followed by the relatively young Digital Heritage series which took place for the first time in 2013.

Among journals, those published by the ISPRS were mentioned as most relevant, especially the ISPRS archives and annals. A major influencing factor for that may be that all proceedings of CIPA symposia and workshops were published in special issues of these journals. Furthermore, the ACM Journal on Computing and Cultural Heritage (JOCCH) and the Journal of Archaeological Science were named as relevant. Since conference series were named nearly twice as often as journals, it may be assumed that communication in the field of digital cultural heritage primarily takes place via conferences. In total 531 different publication bodies were named - undoubtedly there exists a large variety of podia of relevance for researchers in the field of digital cultural heritage.

\section{Projects}

Another online survey question was about projects which are estimated as most groundbreaking (c.f. Fig. 5). Similar to publications a wide variety of projects was named as most relevant. With regards to these namings, all top 10 ranked projects were funded by the EU. Focusing on individual endeavours, the most frequently mentioned project is the EPOCH project, followed by Ariadne and Europeana as well as 3D-COFORM. Since most of the mentioned projects were named by only few researchers these findings are relatively weak.

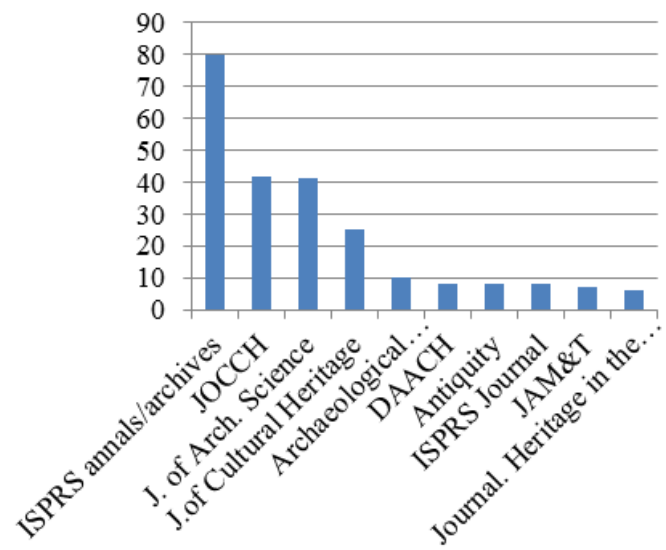

Figure 7. Journals named as "most relevant” (online survey, top $10, n=235$ out of 1382 named publications)

\section{CONCLUSION}

What are findings of relevance from these investigations? Most of the researchers in the field of cultural heritage are Europeans and have a disciplinary background in the humanities and in particular archaeology. Even if there is a wide scope of topics addressed, most of these are around data in terms of data acquisition and management, visualization or analysis. Moreover, digital heritage as scholarly area is primarily defined by publication bodies, repositories and projects. Especially conference series such as CAA or Digital Heritage seem of great importance for scholarly communication. While many single projects were named in the online survey as influencing, only a few were mentioned by multiple researchers. Similarly, there is probably no single institution or method explicitly mentioned as standard - maybe due to the "diverse nature of the methods used” (Long and Schonfeld, 2014, p. 48). 
Some potential weaknesses of these investigations have to be mentioned. Since a sample for the online survey was constructed from authors active in specific conference series, a community around these conferences may only partly represent a community on topics of digital cultural heritage. Furthermore, the classification of the qualitative answers may be biased even if a detailed coding scheme was created and employed.

A future task will be to compare results from the investigations described in this paper with those of literature-based investigations and to further assess phenomena such as the low rate of researchers from computing. Moreover, it seems of particular interest to repeat the survey periodically to study how the field of research will change over time.

\section{ACKNOWLEDGEMENTS}

The research which this paper is based on was part of the junior research group UrbanHistory4D’s activities which has received funding from the German Federal Ministry of Education and Research under grant agreement No 01UG1630.

\section{REFERENCES}

Arnold, D., Geser, G., 2008. EPOCH Research Agenda - Final Report, Brighton.

Beacham, R., Denard, H., Niccolucci, F., 2006. An Introduction to the London Charter, in: Ioannides, M., Arnold, D., Niccolucci, F., Mania, K. (Eds.), Papers from the Joint Event CIPA/VAST/EG/EuroMed Event, pp. 263-269.

Bendicho, V.M.L.-M., 2011. The principles of the Seville Charter XXIII CIPA Symposium - Proceedings.

Cetina, K.K., Reichmann, W., 2015. Epistemic Cultures. 873880 .

Drucker, J., 2013. Is There a "Digital" Art History? Visual Resources 29, 5-13.

European Commission, 2011. Survey and outcomes of cultural heritage research projects supported in the context of EU environmental research programmes. From 5th to 7th Framework Programme. European Commision, Brussels.

Evans, T.L., Daly, P.T., 2006. Digital archaeology. bridging method and theory. Routledge, London [u. a.].

Frischer, B., Dakouri-Hild, A., 2008. Beyond illustration. 2D and 3D digital technologies as tools for discovery in archaeology. Archaeopress, Oxford.

Gläser, J., Laudel, G., 2009. Experteninterviews und qualitative Inhaltsanalyse als Instrumente rekonstruierender Untersuchungen, 3., überarb. Aufl.. ed. VS Verlag für Sozialwissenschaften, Wiesbaden.

Heusinger, L., 1989. Applications of Computers in the History of Art, in: Hamber, A., Miles, J., Vaughan, W. (Eds.), Computers and the History of Art. Mansell Pub., London and New York, pp. 1-22.

Hicks, D., 2006. The Four Literatures of Social Science, in: Moed, H.F., Glänzel, W., Schmoch, U. (Eds.), Handbook of Quantitative Science and Technology Research: The Use of Publication and Patent Statistics in Studies of S\&T Systems. Springer Science \& Business Media, pp. 473-496.
Huvila, I., 2014. Archives, Libraries and Museums in the Contemporary Society: Perspectives of the Professionals, iConference 2014 Proceedings, pp. 45-64.

Kansa, E.C., Kansa, S.W., Watrall, E., 2011. ARCHAEOLOGY 2.0. New approaches to communication \& collaboration. Cotsen digital archaeology.

Kiouss, A., Karoglou, M., Labropoulos, K., Moropoulou, A., Zarnic, R., 2011. Recommendations and Strategies for the Establishment of a Guideline for Monument Documentation Harmonized with the existing European Standards and Codes, XXIII CIPA Symposium - Proceedings.

Knorr-Cetina, K., 1999. Epistemic cultures. how the sciences make knowledge. Harvard University Press, Cambridge.

Kohle, H., 2013. Digitale Bildwissenschaft, Glückstadt.

Krishnan, A., 2009. What are academic disciplines. Some observations on the Disciplinarity vs. Interdisciplinarity debate. University of Southampton. National Centre for Research Methods, Southhampton.

Lave, J., Wenger, E., 1991. Situated Learning: Legitimate Peripheral Participation. Cambridge University Press, Cambridge

Long, M.P., Schonfeld, R.C., 2014. Supporting the Changing Research Practices of Art Historians. Ithaka S+R.

Mayring, P., 2008. Qualitative Inhaltsanalyse. Grundlagen und Techniken, 10. Auflage ed, Weinheim.

Mieg, H.A., Näf, M., 2005. Experteninterviews, 2. Auflage ed, Zürich.

Münster, S., 2017. Employing bibliometric methods to identify a community, topics and protagonists of digital 3D reconstruction in the humanities, iConference 2017, Wuhan.

Münster, S., Ioannides, M., 2015. The scientific community of digital heritage in time and space, in: Guidi, G., Scopigno, R., Torres, J.C., Graf, H. (Eds.), 2nd International Congress on Digital Heritage 2015, Granada.

Münster, S., Niebling, F., 2016. Building a wiki resource on visual knowledge related knowledge assets, in: Spender, J., Schiuma, G., Nönnig, J.R. (Eds.), Proceedings of the 11th International Forum on Knowledge Asset Dynamics (IFKAD 2016) Dresden, Germany. June 15-17th 2016. University of Basilicata, Dresden, pp. 1606-1618.

n.n., 1991. CERIF (Common European Research Project Information Format). Official Journal of the European Communities L189.

NCES IPEDS, 2010. Classification of Instructional Programs (CIP).

Organisation for Economic Co-operation and Development, 2002. Frascati Manual. Proposed Standard Practice for Surveys on Research and Experimental Development. OECD Publications Service, Paris.

Pfarr, M., 2009. Dokumentationssystem für Digitale Rekonstruktionen am Beispiel der Grabanlage Zhaoling, Provinz Shaanxi, China (Dissertation), Darmstadt. 
Scollar, I., 1997. 25 Years of Computer Applications in Archaeology. CAA.

Sürül, A., Özen, H., Tutkun, M., 2003. ICOMOS digital database of the Cultural Heritage of Trabzon. XIX CIPA Symposium - Proceedings.

Svensson, P., 2010. The Landscape of Digital Humanities. Digital Humanities Quarterly 4.

Terras, M., 2006. Disciplined: Using Curriculum Studies to Define 'Humanities Computing. Literary and Linguistic Computing 21, 229-246.

Terras, M., Nyhan, J., Vanhoutte, E., 2013. Defining Digital Humanities. A Reader. Ashgate.

Weingart, S., 2016. Submissions to DH2017, The Scottbot Irregular.

Wenger, E., 1998. Communities of Practice: Learning, Meaning, and Identity. Cambridge University Press, Cambridge. 